\title{
Rare adult pancreatic hemangioma: review of the literature with a case report
}

\author{
Junfeng Zhou, Zhong Chen^ \\ Department of Hepatobiliary Surgery, The 960th Hospital of PLA, Jinan, China \\ Correspondence to: Zhong Chen, MD. Department of Hepatobiliary Surgery, The 960th Hospital of PLA, Shifan Street 25, Tianqiao District, Jinan \\ 250031, China. Email: 276290546@qq.com.
}

\begin{abstract}
Adult pancreatic hemangioma is an especially rare benign tumor that is hard to diagnose through imaging examinations, meanwhile its histopathological and immunohistochemical studies have rarely been reported. At this time, only 29 cases in 27 publications have been reported. We report a new case as well as review these literatures. A 71-year-old woman came to our hospital with slight pain on left upper abdomen for three days. But the results obtained from the physical or laboratory examination were all negative so that her symptoms could not be explained clearly. The imaging examinations including ultrasonography and computed tomography both showed a mixed mass in the neck of the pancreas. The preoperative diagnosis of cystadenoma or adenocarcinoma was made, with high suspicious of malignancy. The patient underwent a central pancreatectomy with pancreatojejunostomy, but the pathologic diagnosis was pancreatic hemangioma. The immunohistochemical examination found the positive benign vascular markers (CD31, CD34) and negative lymphocyte markers (D2-40). Moreover, Ki-67 negativity also revealed its benign nature. After 36 months of follow-up, the patient has no complaints for abdominal pain. In conclusion, adult pancreatic hemangioma is extremely rare without any specific clinical manifestations. It is usually diagnosed postoperatively by histological examination and immunohistochemical studies. Imaging examinations, including computed tomography and magnetic resonance imaging, can't give definite conclusion. Endoscopicultrasound guided fine needle aspiration is conditionally worth doing, which can give some hints and exclude the malignancy of the lesion. If malignancy can be safely ruled out, the surgical decision must be made according to risk-benefit analysist. Maybe close observation and regular follow-up are more beneficial options.
\end{abstract}

Keywords: Pancreatic; hemangioma; adult; case report

Submitted Feb 26, 2020. Accepted for publication Jul 30, 2020.

doi: $10.21037 / g s-20-281$

View this article at: http://dx.doi.org/10.21037/gs-20-281

\section{Introduction}

Hemangiomas are benign tumors which comprised a large quantity of different blood vessels and can be found in all organs. Among them, hepatic hemangiomas account for nearly one-third of these internal lesions. Pancreatic hemangiomas are extremely rare, collectively accounting for only $0.1 \%$ in all pancreatic tumors (1). They are rarely suspected or clinically diagnosed because of their low morbidity and nonspecific symptoms. As a type of pancreatic tumor, they may also cause clinical symptoms associated with the pancreas. On the other hand, there is no exclusive imaging characteristics of ultrasound, angiography, computed tomography, or magnetic resonance imaging. Therefore, it's often difficult to distinguish them from other pancreatic neoplasms, such as intraductal papillary mucinous neoplasms, solid pseudopapillary neoplasms and mucinous cystic neoplasms. Hence, they are finally definitely diagnosed by histological examination and immunohistochemical studies. To date, only 27 publications for 29 cases of adult pancreatic

\footnotetext{
^ ORCID:0000-0001-8952-1993.
} 

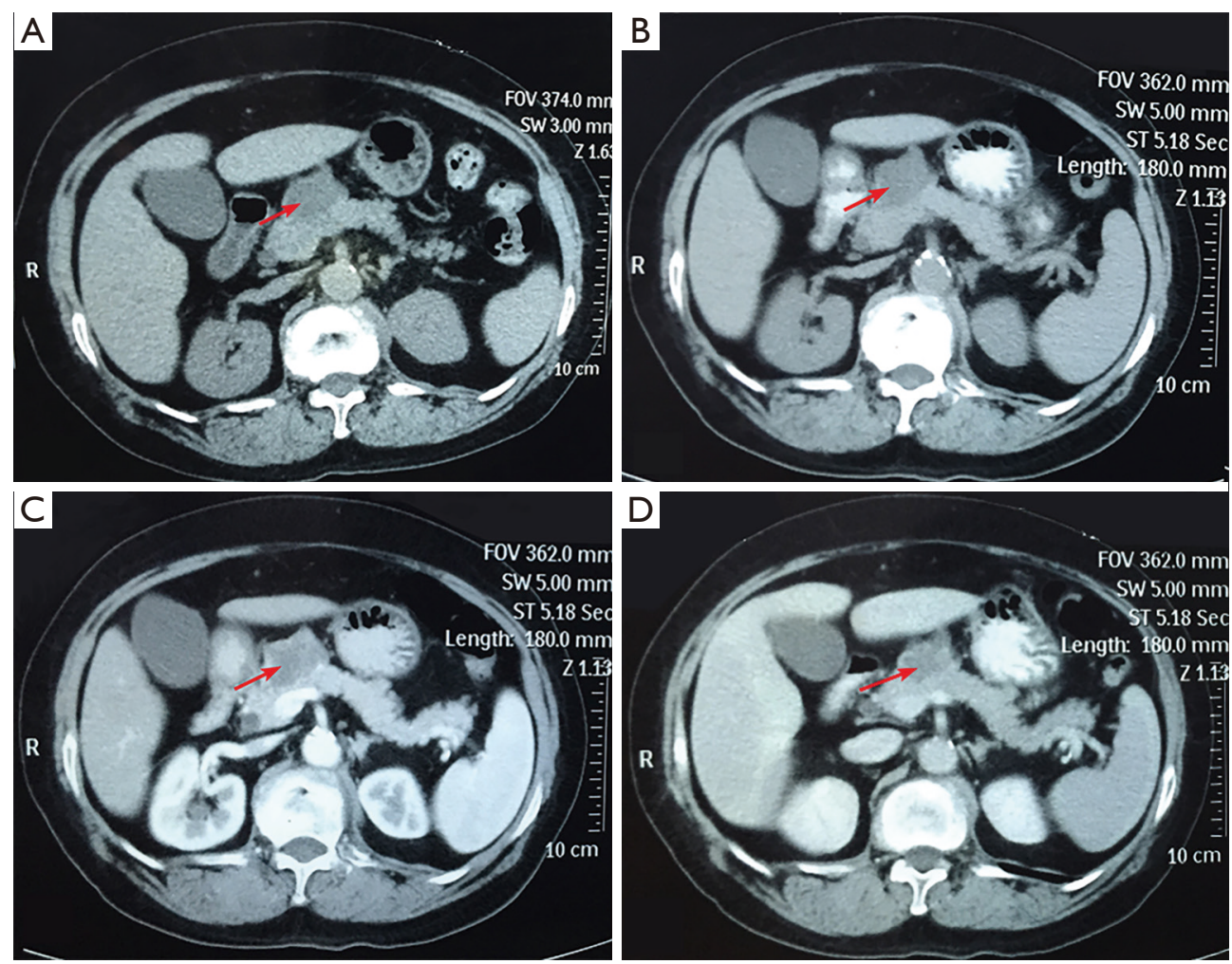

Figure 1 Computed tomography showing a pancreatic mass (red arrows).

hemangiomas have been found in the literature (showed in Table 1). Since there are no malignant cases published to date, surgical resection may be avoided if the diagnosis can be firmly made. The aim of the present review on the published case reports of pancreatic hemangioma is to summaries the clinical characteristics of this unusual type of neoplasm. In the present report, we describe a new case of adult hemangiomas located in the neck of the pancreas. We present the following case in accordance with the CARE Reporting Checklist (available at http://dx. doi. org/10. 21037/gs-20-281). Additionally, we reviewed the 29 cases of adult pancreatic cavernous hemangioma reported in the literature in an attempt to identify tumor characteristics.

\section{Case presentation}

A 71-year-old woman came to our hospital with slight pain on left upper abdomen for 3 days. She had no past medical histories of diseases or surgeries. The family and psychosocial history including relevant genetic information were not special either. She had no relevant past interventions. Her laboratory test results including blood routine examination, hepatic and renal function tests, were all within normal ranges. The levels of tumor marker including carbohydrate antigen (CA) 19-9, alpha-fetoprotein (AFP) and carcinoembryonic antigen (CEA) also reveal no abnormality. A physical examination also failed to reveal any abnormality. No abdominal tenderness or mass was found. An abdominal ultrasonography (US) indicated a mixed pancreatic head mass measuring about $3.2 \times 3 \mathrm{~cm}$, cholecystitis with gallstones, mild dilated common biliary duct measuring about $1 \mathrm{~cm}$, and normal pancreatic duct. An abdominal computed tomography (CT) scan confirmed a well-defined tumor in the neck of the pancreas measuring $3.3 \times 2.5 \mathrm{~cm}$ (Figure 1A,B). It showed a peripheral filling and strong enhancement in the arterial phase (Figure 1C). However, it produced heterogeneous enhancement in the venous and late phase without centripetal filling effect (Figure 1D). The diagnostic challenge is that there are too many similar diseases. The clinical diagnosis of cystadenoma or adenocarcinoma was made, with high suspicious of malignancy. Other differential diagnoses, such as solid pseudopapillary neoplasms, intraductal papillary mucinous neoplasms and mucinous cystic neoplasms were also 


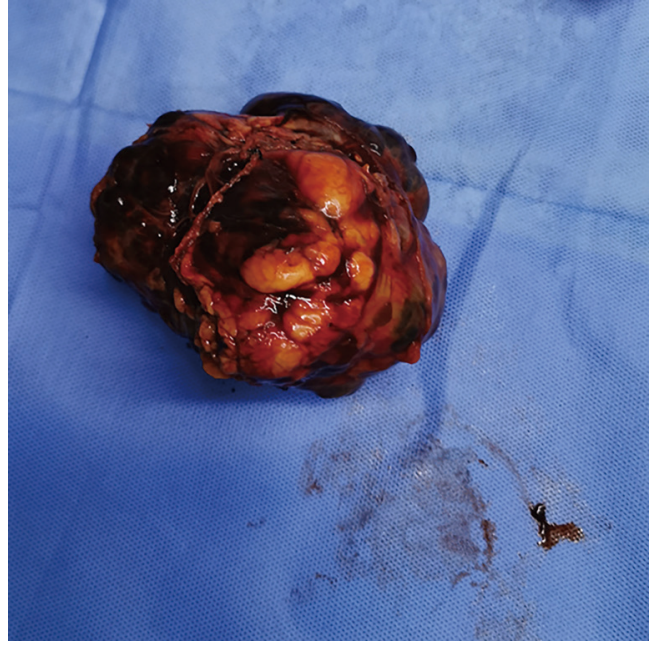

Figure 2 Surgical sample: a reddish tumor comprising multilocular cysts with harder granulation tissue surrounded. considered, except for pancreatic hemangioma which has a good prognosis. The patient was recommended a surgical resection due to the risk of malignancy. The operation was successfully taken in the fourth day. During the operation, the mass including the adhesive pancreatic parenchyma was found in the pancreatic neck with about $4 \mathrm{~cm}$ of diameter (Figure 2). It looked like a benign cystic tumor with a complete capsule. Finally, the patient underwent a central pancreatectomy with pancreatojejunostomy. The definite histological examination confirmed a pancreatic hemangioma. Surgical sample revealed a reddish tumor comprising multilocular cysts with harder granulation tissue surrounded. Histology revealed the lesion comprised blood vessels of different size, ranging from glomus-like capillaries to large, cavernous spaces (Figure 3A). The CD31 and CD34 immunohistochemical studies were strongly positive,
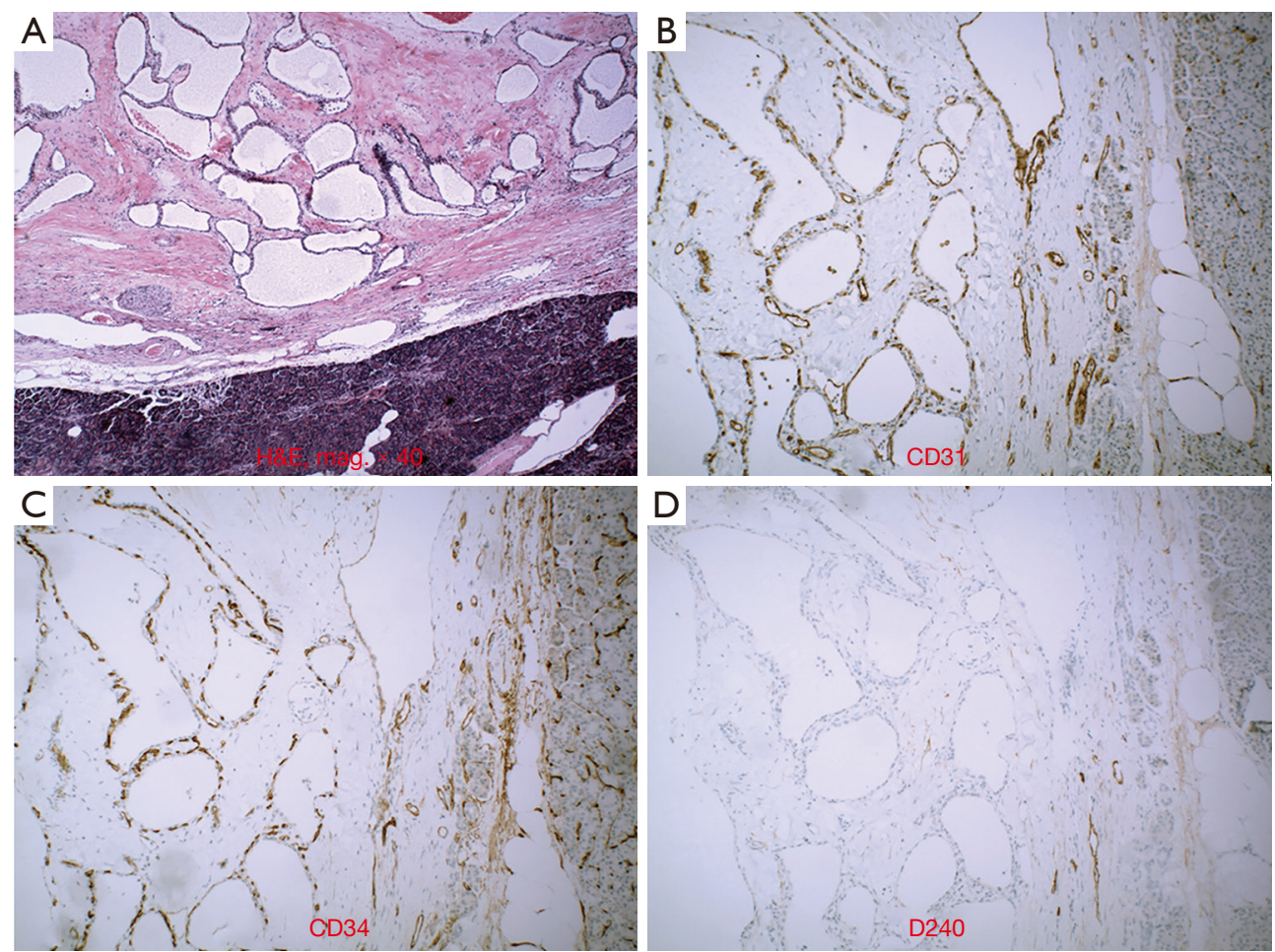

Figure 3 Pancreatic hemangioma: histology and immunohistochemistry $(\times 40)$. (A) Multiple vascular spaces containing blood in a welldemarcated area and surrounded by fatty tissue (hematoxylin \& eosin, $\times 40$ ). (B,C) Immunohistochemical stain for CD31 and CD 34 showing positive staining of the vascular wall lining and lumen $(\times 40)$. (D) Immunohistochemical stain for D240 showing negative staining of the vascular wall lining and lumen $(\times 40)$. 


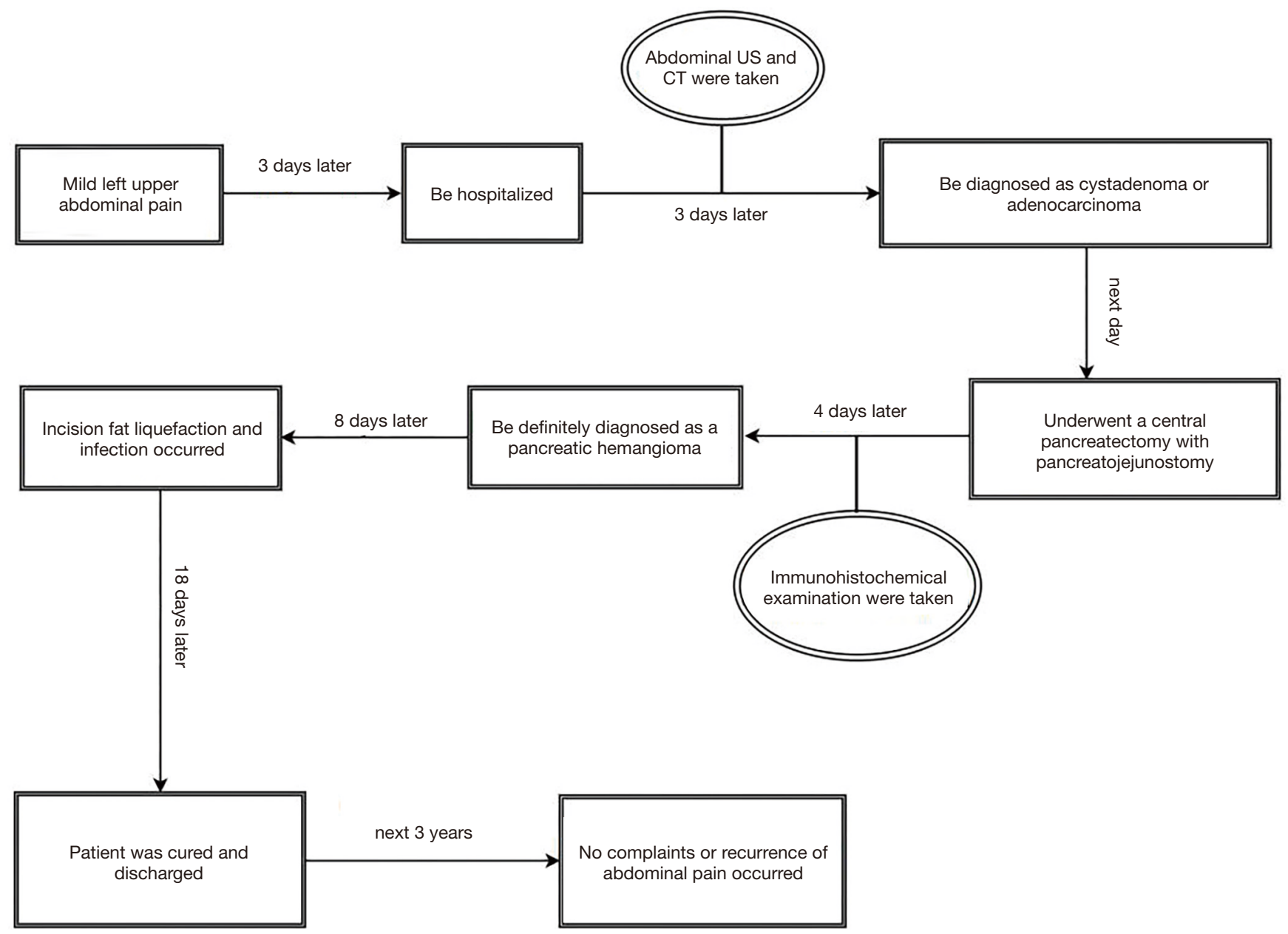

Figure 4 The timeline for the case.

indicating an endothelial origin (Figure $3 B, C$ ). D2-40, a lymphatic endothelium marker, was negative and $\mathrm{Ki}-67$, an antigen assessing malignancy of the tumor, was about $3 \%$ (Figure 3D). There was no evidence of malignancy. The postoperative course was uneventful except for the incision fat liquefaction and infection. The length of postoperative hospital stay was 26 days. Then the patient was followed up for 36 months without complaints or recurrence of abdominal pain. Regular CT examination failed to find any abnormality either. The patient's compliance is good and there are no adverse or unanticipated events.

Timeline: Mild left upper abdominal pain was felt 3 days ago-The clinical diagnosis of cystadenoma or adenocarcinoma was made after different examinations in the first 3 hospital days-A central pancreatectomy with pancreatojejunostomy was taken in the 4th day-The definite histological examination confirming a pancreatic hemangioma was made in the 8th day-The incision fat liquefaction and infection occurred in the 12th day-Patient was cured and discharged in the 30th day-No complaints or recurrence of abdominal pain occurred in the next 3 years. It is shown in Figure 4.

All procedures performed in studies involving human participants were in accordance with the ethical standards of the institutional and/or national research committee(s) and with the Helsinki Declaration (as revised in 2013). Written informed consent was obtained from the patient.

\section{Discussion}

Pancreatic hemangioma is an uncommon type of primary cystic neoplasm, which generally arises in childhood. 
Hemangiomas have been reported to developed in three phases: the proliferating phase (the capillaries increase rapidly in number and continuously grows up until the child is one year old), the involuting phase (growth declines and reveals inevitable regression until the age of one to five years) and the involuted phase (improvement continues until the child is six to twelve years old, and ultimately a fibro-fatty residuum was produced by adulthood) (29). For this reason, pancreatic hemangioma is hardly to be found in adults. Moreover, pancreatic hemangiomas are especially difficult to give clinical diagnosis. The aim of the present review based on the published case reports of pancreatic hemangioma is to summaries the clinical characteristics of this unusual type of neoplasm. A search of the literature from PubMed, Google Scholar and relevant articles using the keywords "pancreatic hemangioma" was made, and their references were also reviewed. We only find 29 cases from 27 reports have been reported in the literature since 1939 including 3 cases mentioned in a Chinese article by $\mathrm{Xu}$ et al. (10). Clinical characteristics of all cases are summarized in Table 1. According to these cases, just as other hemangiomas, the pancreatic hemangioma is also more commonly found in women (23 in this series, $77 \%)$, sometimes during pregnancy $(15,23)$, indicating the importance of excess of female sex hormones in these tumors (30). The average age was 51 years (18-79 years) and most of the cases $(20 / 30,67 \%)$ between 30 and 70 years. The largest diameter ranged from 0.6 to $20 \mathrm{~cm}$, and most of these cases are not less than $5 \mathrm{~cm}(20 / 30,67 \%)$. Most patients can't be symptomatic for a long time until the tumor grow large enough to cause relevant symptoms. The most common symptom is still abdominal pain (20/30, $67 \%)$, usually in the epigastric region and sometimes irradiating to the back. Other infrequent symptoms such as nausea, vomiting, early satiety, abdominal distension, eating choke and jaundice are caused by occupied tumor. More infrequent symptoms, some of which may be not relevant, such as hematemesis, malaise, thrombocytopenia, dizziness, palpitations, left iliac fossa pain and fever can be also found in different cases. Only 4 cases have no symptoms $(2,10,17,25)$, one found at autopsy (2), while the other three found in incidental imaging examinations. Excluding the one found at autopsy, other asymptomatic cases are all suspicious of malignancy. Maybe these asymptomatic tumors are relatively small and atypical so that the imaging examinations differed more difficultly.

The majority of these cases had been identified by CT $(23 / 30,77 \%)$, followed by ultrasonography or endoscopic ultrasonography (EUS) $(21 / 30,70 \%)$, and magnetic resonance imaging (MRI) that applied in more recent cases $(10 / 30,33 \%)$. Other imaging examinations, such as angiography, gastrointestinal endoscopy, endoscopic retrograde cholangiopancreatography (ERCP), Abdo plain $\mathrm{X}$-ray, cholangiography can be also found in a few cases. Under ultrasound examination, the tumor presents as a hyperechogenic mass with no or low blood flow, in contrast to the adequate blood supply for malignant tumors. By MRI and CT, the tumor usually appears as a well-demarcated, alveolar or multilocular cystic lump, with no expansion of main pancreatic duct. Besides, the pancreatic hemangioma appears as a hypervascular mass and usually shows strong enhancement in the contrast-enhanced arterial phase of CT, as in our case. But this finding was not confirmed in some other cases $(6,10,11,13,16,17,21)$. The reason may be that arteriovenous shunting and neovascularization slow blood flow through cavernous vascular areas of cystic pancreatic tumors and the signal intensity in the arterial phase is impacted by the ratio of cystic to solid tumor tissue, which influences the relative degree of vascularity (21). So, it is still easily misdiagnosed solely based on contrast-enhanced CT. Using enhanced MRI, pancreatic hemangiomas can present hypointense on unenhanced $\mathrm{T} 1 \mathrm{w}$ and hyperintense on $\mathrm{T} 2 \mathrm{w}$ images, meanwhile they show only moderate gadoliniumenhancement with washout on delayed phase images (9). Thus, it is necessary to undertake both CT and MRI for a more reliable diagnosis. However, it is still difficult to make a definite diagnosis in some cases $(11,17,21,22,27)$ though both CT and MRI were undertaken. Endoscopicultrasound guided fine needle aspiration (EUS-FNAB) was undertaken in 3 reports $(13,18,22)$, which can give some hints and exclude the malignancy of the lesion. It is worth doing if conditional.

The therapies to hemangiomas are variable. Unlike recognized observation for pediatric hemangiomas, there are no definitive standards for the treatment of pancreatic hemangiomas in adults. Yet, due to their risk of sudden hemorrhage and the uncertain differential diagnosis with epithelial tumors, surgical resection is often recommended. The surgical method is chosen mostly based on the location of the pancreatic hemangioma, and also influenced by tumor size. Upon reviewing previous literatures, the pancreatic hemangioma is most located in or related to the head of the pancreas (14 in this series, $47 \%$ ), which may cause clinical symptoms more easily. When the tumor is located at head of the pancreas, pancreaticoduodenectomy is a major option. When the tumor is located at body or 
Table 1 Pancreatic hemangiomata previously reported in literature

\begin{tabular}{|c|c|c|c|c|c|c|c|c|c|}
\hline Reference & Age & Sex & Presentation & Imaging & Clinical diagnosis & Location/size (cm) & Treatment & Histology & Immuno-histochemistry \\
\hline Ranstrom 1939 (2) & 61 & $\mathrm{~F}$ & - & - & At autopsy & Head $/ 7 \times 7$ & - & - & - \\
\hline Ringoir 1961 (3) & 71 & $\mathrm{~F}$ & Hematemesis, melena, Abdominal pain & Abdo plain X-ray, cholangiography & Not clear & Head/15 & Retrocolic- gastroenterostomy, vagotomy & Hemangioma & - \\
\hline Colardyn 1972 (4) & 42 & M & Malaise & Abdo plain X-ray, angiography & Not clear & Body, tail/not mentioned & Conservative & - & - \\
\hline Mangin 1985 (5) & 62 & $\mathrm{~F}$ & Malaise, nausea, thrombocytopenia & US, ERCP, native CT & Not clear & Head, body, tail/20×7 & Resection of the tumor & Hemangioma & - \\
\hline Dageforde 1991 (6) & 79 & $\mathrm{~F}$ & Abdominal pain & US, ERCP, angiography, enhanced CT & Hemangioma & Body and tail junction $/ 6 \times 3$ & Observation & - & - \\
\hline Kobayashi 1991 (7) & 30 & M & Abdominal pain and distension & US, enhanced CT, angiography, MRI & Possible cavernous hemangioma & Head 20 & Pancreatico-duodenectomy & Hemangioma & - \\
\hline Chang 2003 (8) & 70 & $\mathrm{~F}$ & Epigastric pain and tenderness & enhanced $\mathrm{CT}$, angiography & Cystic adenocarcinoma & Body and tail junction $/ 4 \times 3.2$ & Distal subtotal pancreatectomy & Hemangioma & Factor VIII-related Ag \\
\hline Plank 2006 (9) & 36 & M & Abdominal pain and jaundice & enhanced CT, MRI, intraoperative US & Neuroendocrine tumor & $\mathrm{Head} / 3$ & Laparotomy without resection, observation & - & - \\
\hline \multirow[t]{3}{*}{ Xu 2008 (10) } & 60 & $\mathrm{~F}$ & Abdominal pain and fever & US, enhanced CT & Cystic adenoma or adenocarcinoma? & Tail/ $2 \times 2$ & Distal spleno-pancreatectomy & Hemangioma & CD31, CD34, Factor VIII-related Ag \\
\hline & 41 & $\mathrm{~F}$ & - & us & Cystic tumor or Islet cell carcinoma? & Body $/ 2.5 \times 2$ & Distal subtotal pancreatectomy & Hemangioma & CD31, CD34, Factor VIII-related Ag \\
\hline & 30 & $\mathrm{~F}$ & Abdominal pain and Eating choke & us & Cystic or solid tumor? & Head $/ 6 \times 5$ & Pancreatico-duodenectomy & Hemangioma & CD31, CD34, Factor VIII-related Ag \\
\hline Mundinger 2009 (11) & 45 & $\mathrm{~F}$ & $\begin{array}{l}\text { Stabbing epigastric pain } \\
\text { radiating through to back }\end{array}$ & Enhanced CT, MRI & $\begin{array}{l}\text { Duplication cyst, cystic GIST, } \\
\text { paraganglioma }\end{array}$ & Head/6.2×5.3 & $\begin{array}{l}\text { Pylorus preserving } \\
\text { pancreatico-duodenectomy }\end{array}$ & Hemangioma & $\mathrm{CD} 31, \mathrm{CD} 34$ \\
\hline Jarboui 2010 (12) & 60 & $\mathrm{~F}$ & nausea, diffuse abdominal pain, and fever & US, enhanced CT, EUS & Pancreatic cystic lesion & Body/2.3×1.8 & distal spleno-pancreatectomy & Hemangioma & CD31, CD34 \\
\hline Lee 2011 (13) & 49 & $\mathrm{~F}$ & Dizziness, palpitation & US, enhanced CT, EUS-FNAB & Cystic tumor & Body/5 & Central pancreatectomy & Hemangioma & CD34 \\
\hline Weidenfeld 2011 (14) & 73 & $\mathrm{~F}$ & Pain, nausea & US, enhanced CT & Cystic tumor & $\mathrm{Head} / 5$ & Whipple's procedure & Hemangioma & CD31, CD34, Factor VIII-related Ag \\
\hline Franzoni 2012 (15) & 19 & $\mathrm{~F}$ & large hematemesis & Gastrointestinal endoscopy, MRI, US & Cystadenoma & Tail/ $11 \times 9 \times 8$ & distal pancreatectomy and splenectomy & Hemangioma & - \\
\hline Lu ZH 2013 (17) & 23 & $\mathrm{~F}$ & - & US, enhanced CT, MRI & Not clear & Head $/ 5.4 \times 5 \times 3$ & Subtotal pancreatectomy & Hemangioma & - \\
\hline Bursics $2013(18)$ & 72 & M & Pain, jaundice & US, enhanced CT, ERCP & Cystic tumor, possibly IPMN & Head and part of duodenum $/ 8$ & Pylorus preserving pancreatico-duodenectomy & Hemangioma & CD31, CD34 \\
\hline Naito 2014 (19) & 40 & $\mathrm{~F}$ & Abdominal pain & Enhanced CT & Cystic neoplasm & Body and tail/10 & Pancreatectomy & Hemangioma & $\mathrm{CD} 31, \mathrm{CD} 34$ \\
\hline Figueroa 2014 (20) & 52 & $\mathrm{~F}$ & Abdominal pain and early satiety & US, enhanced CT & Highly suspicious of malignancy & Head $/ 8 \times 6.5 \times 6$ & pylorus preserving pancreatoduodenectomy & Hemangioma & - \\
\hline Lu T 2015 (21) & 28 & $\mathrm{~F}$ & Epigastric pain & Enhanced CT, MRI & $\begin{array}{l}\text { Cystadenoma or pseudocyst with } \\
\text { intracystic hemorrhage }\end{array}$ & Body and tail/10×8 & Subtotal pancreatectomy, splenectomy & Hemangioma & - \\
\hline Mondal 2015 (22) & 18 & $\mathrm{~F}$ & $\begin{array}{l}\text { Stabbing epigastric pain radiating } \\
\text { through to back, Nausea and emesis }\end{array}$ & $\begin{array}{l}\text { Native CT, Contrast MRI, MRCP, } \\
\text { EUS-FNAB }\end{array}$ & Inflammatory benign cyst & $\begin{array}{l}\text { Head, uncinate } \\
\text { process } / 6 \times 4 \times 3.5\end{array}$ & $\begin{array}{l}\text { Pylorus preserving } \\
\text { pancreatico-duodenectomy }\end{array}$ & Hemangioma & CD31, CD34 \\
\hline Kim 2015 (23) & 68 & $\mathrm{~F}$ & - & Enhanced CT & Neuroendocrine tumor or metastasis & Tail/0.6×0.5 & Nephrectomy, distal pancreatectomy & Hemangioma & CD31, CD34, factor VIII \\
\hline Soreide 2015 (24) & 38 & $\mathrm{~F}$ & $\begin{array}{l}\text { Left epigastric pain, nausea, } \\
\text { palpable left subcostal mass }\end{array}$ & US, MRI & $\begin{array}{l}\text { Solid pseudopapillary epithelial } \\
\text { neoplasm }\end{array}$ & 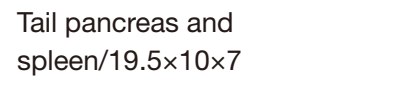 & Distal pancreatectomy, splenectomy & Hemangioma & CD31, CD34 \\
\hline Bratu 2016 (25) & 64 & M & $\begin{array}{l}\text { Acute upper abdominal pain, } \\
\text { weight loss of } 5 \mathrm{~kg} \text { (in } 2 \text { months) }\end{array}$ & US, endoscopy, enhanced CT & Pancreatic adenocarcinoma & Body/3.2×1.9 & Surgical resection of the lesion & Hemangioma & - \\
\hline Al Warith 2017 (26) & 71 & $\mathrm{~F}$ & Left iliac fossa pain & Native CT, MRI, EUS & Mucinous neoplasia & Tail/2.4 & $\begin{array}{l}\text { Laparoscopic distal pancreatectomy, } \\
\text { splenectomy }\end{array}$ & Hemangioma & - \\
\hline Raymundo 2018 (27) & 36 & M & Lumbar pain & Enhanced CT, MRI, ERCP & Neuroendocrine tumour & Body and tail/2.4×2.2 & Distal pancreatectomy, splenectomy & Hemangioma & CD31, ERG \\
\hline Lianyuan 2019 (28) & 63 & M & $\begin{array}{l}\text { Left upper abdominal pain and } \\
\text { defecation unformed }\end{array}$ & $\begin{array}{l}\text { Enhanced CT, } \\
\text { EUS }\end{array}$ & Cystic tumor & Head $/ 10 \times 5 \times 5$ & Pancreatico-duodenectomy & Hemangioma & CD31, CD34, factor VIII, ERG \\
\hline Present case & 71 & $\mathrm{~F}$ & Left upper abdominal pain & Enhanced CT, US & Cystadenoma or adenocarcinoma & Neck/3.5×2.7×2.5 & Central pancreatectomy & Hemangioma & $\mathrm{CD} 31, \mathrm{CD} 34$ \\
\hline
\end{tabular}


tail of the pancreas, distal or subtotal pancreatectomy is indicated and combined splenectomy is sometimes necessary. If malignancy can be safely excluded and the mass can be separated fully from pancreas, surgical resection of the lesion with or without surrounded pancreatic tissues is also feasible. Using ultrasound and rapid pathological examination during the operation can also help in choosing the best surgical approaches (denucleation, other more conservative surgical procedures or an extended resection). In our case, the tumor is located in the neck of the pancreas with complete envelope. A central pancreatectomy was undertaken, with head, part of body and tail of pancreas left. Our patient recovered relatively smoothly, though she had a postoperative complication of the incision fat liquefaction and infection, which led to longer hospital stays and higher medical cost. However, the morbidity rate of the patients who underwent pancreaticoduodenectomy was higher than that of the patients who underwent distal pancreatectomy (34.7\% vs. $27.8 \%, \mathrm{P}<0.05)$ (31). Therefore, if the tumor is located in the pancreatic head, which is highly suspicious of hemangioma and it cause few manageable symptoms, close observation and regular medical follow-up must be more suitable choices.

After the surgery, as our case, the microscopic specimens usually shows that blood-filled spaces are separated by fibrous connective tissue and this is a typical characteristic of hemangioma (25). For the tumor can be further definitely diagnosed, immunohistochemistry is usually needed. There are some common markers to identify hemangioma. The existence of the factor VIII-related antigen was reported as a vascular endothelium marker by Chang et al. (8). After that, Mundinger et al. (11) reported that the endothelial markers CD31 and CD34 were also expressed in hemangioma. In our patient, immunohistochemical results were positive for CD31 and CD34. On the other hand, D2-40, a lymphatic endothelium marker, was negative and $\mathrm{Ki}-67$, an antigen assessing malignancy of the tumor, was about $3 \%$. These findings indicated that the tumor mass was a hemangioma. Finally, pancreatic hemangioma is definitely diagnosed by histological examination and immunohistochemical studies with positive markers CD31, CD34 or factor VIII-related antigen.

\section{Conclusions}

In conclusion, adult pancreatic hemangioma is especially rare and it have no specific clinical symptoms. It is usually diagnosed postoperatively by histological examination and immunohistochemical studies. Imaging examinations, including CT and MRI, can't give definite conclusion. In contrast to other hemangiomas, the CT signs may not show a typical and strong enhancement in the contrast-enhanced arterial phase. EUS-FNAB is conditionally worth doing, which can give some hints and exclude the malignancy of the lesion. Since the pancreatic surgeries have relatively high rate of morbidity, which can lead to longer hospital stays and higher medical cost, more cautious decision should be made. If malignancy can be safely ruled out, the surgical decision must be made according to risk-benefit analysist. Maybe close observation and regular follow-up are more beneficial options.

\section{Patient perspective}

The patient appreciated our surgery because it not only relieved the pain, but also removed her concerns for the tumor. Although she had a postoperative complication of the incision fat liquefaction and infection, which led to longer hospital stays and higher medical cost, she still thought it is worthwhile.

\section{Acknowledgments}

Funding: None.

\section{Footnote}

Reporting Checklist: The authors have completed the CARE reporting checklist. Available at http://dx.doi.org/10.21037/ gs-20-281

Conflicts of Interest: Both authors have completed the ICMJE uniform disclosure form (available at http://dx.doi. org/10.21037/gs-20-281). The authors have no conflicts of interest to declare.

Ethical Statement: The authors are accountable for all aspects of the work in ensuring that questions related to the accuracy or integrity of any part of the work are appropriately investigated and resolved. All procedures performed in studies involving human participants were in accordance with the ethical standards of the institutional and/or national research committee(s) and with the Helsinki Declaration (as revised in 2013). Written informed consent was obtained from the patient.

Open Access Statement: This is an Open Access article 
distributed in accordance with the Creative Commons Attribution-NonCommercial-NoDerivs 4.0 International License (CC BY-NC-ND 4.0), which permits the noncommercial replication and distribution of the article with the strict proviso that no changes or edits are made and the original work is properly cited (including links to both the formal publication through the relevant DOI and the license). See: https://creativecommons.org/licenses/by-nc-nd/4.0/.

\section{References}

1. Robbins S, Kumar V. Robbins and Cotran pathologic basis of disease. 8th ed. Philadelphia, PA: Saunders/Elsevier, 2010.

2. Ranstrom V. Haemangioma cavernosum pancreatitis (in German). Zentralblatt für allgemeine Pathologie und pathologische Anatomie 1939;73:33-5.

3. Ringoir S, Derom F, Colle R, et al. Hemangioma of the pancreas. Report of a case. Gastroenterology 1961;41:43-5.

4. Colardyn F, Elewaut A, Van de Velde E, et al. Hemangioma of the pancreas. Tijdschr Gastroenterol 1972;15:260-7.

5. Mangin P, Perret M, Ronjon A. Hemangioma du pancreas. J Radiol 1985;66:381-4.

6. Dageforde J, Gmelin E, Otte M. Hemangioma of the pancreas (in German). Fortschr Rontgenstr 1991;154:332-3.

7. Kobayashi H, Itoh T, Murata R, et al. Pancreatic cavernous hemangioma: CT, MRI, US, and angiography characteristics. Gastrointest Radiol 1991;16:307-10.

8. Chang WT, Lee KT, Yang SF. Cavernous hemangioma of the pancreas: report of a case. Pancreas 2003;26:310-2.

9. Plank C, Niederle B, Ba-Ssalamah A, et al. Pancreatic hemangioma: imaging features with contrast-enhanced CT and with gadolinium- and mangafodipir-enhanced MRI. European Journal of Radiology Extra 2006;57:59-62.

10. Xu Q, Wang CF, Zhao P, et al. The diagnosis and treatment of pancreatic cavernous hemangioma. Zhonghua Yi Xue Za Zhi 2008;88:28-30.

11. Mundinger GS, Gust S, Micchelli ST, et al. Adult pancreatic hemangioma: case report and literature review. Gastroenterol Res Pract 2009;2009:839730.

12. Jarboui S, Salem A, Gherib BS, et al. Hemangioma of the pancreas in a 60-year-old woman: a report of a new case. Gastroenterol Clin Biol 2010;34:569-71.

13. Lee J, Raman K, Sachithanandan S. Pancreatic hemangioma mimicking a malignant pancreatic cyst.
Gastrointest Endosc 2011;73:174-6.

14. Weidenfeld J, Zakai BB, Faermann R, et al. Hemangioma of pancreas: a rare tumor of adulthood. Isr Med Assoc $\mathrm{J}$ 2011;13:512-4.

15. Franzoni L, Villar C, Carraretto F, et al. Pancreatic hemangioma manifesting as variceal gastroesophageal bleeding during pregnancy: case report. GED Gastroenterol Endosc Dig 2012;31:142-5.

16. Bursics A, Gyokeres T, Bely M, et al. Adult hemangioma of the pancreas: difficult diagnosis of a rare disease. Clin J Gastroenterol 2013;6:338-43.

17. Lu $\mathrm{ZH}, \mathrm{Wu} \mathrm{M}$. Unusual features in an adult pancreatic hemangioma: CT and MRI demonstration. Korean J Radiol 2013;14:781-5.

18. Malik M, Ahmed I, Kurban L. pancreatic hemangioma - a case report. J Gastroenterol Hepatol Research 2013;2:545-8.

19. Figueroa RM, Lopez GJ, Servin TE, et al. Pancreatic hemolymphangioma. JOP 2014;15:399-402.

20. Naito $Y$, Nishida N, Nakamura $Y$, et al. Adult pancreatic hemangioma: A case report. Oncol Lett 2014;8:642-4.

21. Lu T, Yang C. Rare case of adult pancreatic hemangioma and review of the literature. World J Gastroenterol 2015;21:9228-32.

22. Mondal U, Henkes N, Henkes D, et al. Cavernous hemangioma of adult pancreas: A case report and literature review. World J Gastroenterol 2015;21:9793-802.

23. Soreide JA, Greve OJ, Gudlaugsson E. Adult pancreatic hemangioma in pregnancy--concerns and considerations of a rare case. BMC Surg 2015;15:119.

24. Bratu A, Zaharia C, Cristian D. a case of pancreatic hemangioma in adult which mimics adenocarcinoma of the pancreas. Austin J Gastroenterol 2016;3:1-4.

25. Kim SH, Kim JY, Choi JY, et al. Incidental detection of pancreatic hemangioma mimicking a metastatic tumor of renal cell carcinoma. Korean J Hepatobiliary Pancreat Surg 2016;20:93-6.

26. Al Warith A, Xavier L, rgis F. report of a case of pancreatic hemangioma: a difficult preoperative diagnosis. Int J Case Rep Imag 2017;8:575-8.

27. Raymundo SRO, Hussain KMK, Hussein KG, Kuga ML. Rare case of adult pancreatic haemangioma and literature review. BMJ Case Rep 2018;2018:bcr2018226456.

28. Lianyuan T, Yafeng W, Haibo Y, et al. Adult pancreatic cavernous hemangioma: case presentation of a benign tumor with a complex composition. BMC Gastroenterol 2019;19:197.

29. Takahashi K, Mulliken JB, Kozakewich HP, et al. Cellular 
markers that distinguish the phases of hemangioma during infancy and childhood. J Clin Invest 1994;93:2357-64.

30. Glinkova V, Shevah O, Boaz M, et al. Hepatic haemangiomas: possible association with female sex

Cite this article as: Zhou J, Chen Z. Rare adult pancreatic hemangioma: review of the literature with a case report. Gland Surg 2020;9(5):1596-1604. doi: 10.21037/gs-20-281 hormones. Gut 2004;53:1352-5.

31. Kneuertz PJ, Pitt HA, Bilimoria KY, et al. Risk of morbidity and mortality following hepato-pancreatobiliary surgery. J Gastrointest Surg 2012;16:1727-35. 